\title{
THE MEDIATING EFFECT OF COOPERATIVE LEARNING APPLICATION ON THE RELATIONSHIP BETWEEN SOCIAL MEDIA USAGE AND LANGUAGE PROFICIENCY OF STUDENTS
}

\author{
Janrey Mark M. Davin ${ }^{1}$, Mary Ann E. Tarusan, PhD, EdD ${ }^{2}$ \\ University of Mindanao,Davao City
}

Article DOI: https://doi.org/10.36713/epra9479

DOI No: $10.36713 /$ epra9479

\section{Chapter 1 \\ INTRODUCTION \\ Rationale}

Language proficiency is the ability to use language for a variety of communicative purposes. Users with a good command of the language are considered to have a good command of it because they can grasp it without difficulty, communicate a wide range of ideas clearly in speech and writing, and comfortably engage with other speakers (Renandya et al. 618). Thus, educators agree that proficiency in the English language is the basis for success in academic pursuits. Subsequently, Trice reported that international students were isolated from local students and faculty members because of their poor English language skills.

Indeed, language proficiency is a key to academic performance. A person who does not speak English, for instance, may not have an access to the majority of world's known scientific and technological innovations which are written in English. In addition, the importance of English selfconfidence in the process of adjusting to an English-speaking academic environment in a socio-cultural and psychological level has been proven (Yang, Noels, and Saumure 487-506).

Furthermore, pupils learn a language by being exposed to it or by reading it, according to Krashen's Input Hypothesis. If students have a lot of intelligible input, they are more likely to learn and produce the language appropriately. In this study, Filipinos must be overwhelmed with a lot of information through various channels, including social media, where English is frequently used.

Further examining social media usage may provide some insights into how students use social media in learning. Exploring it further may give insights into how students' cooperative learning applications can help the academic community.

\section{Research Objective}

This study aims to determine the mediating effect of cooperative learning application on the relationship between social media usage and language proficiency. The specific objectives are:

1. To assess the level of social media usage of students in terms of:

1.1 habit;

1.2 obligation; and

1.3 knowledge sharing.

2. To ascertain the level of language proficiency of students in terms of:

2.1 spoken tasks;

2.2 comprehension;

2.3 interaction strategies;

2.4 qualities of spoken performance; and

2.5 writing tasks.

3. To measure the level of cooperative learning application of students.

4. To determine the significance of the relationship between;

4.1 social media usage and language proficiency;

4.2 social media usage and cooperative learning application; and

4.3 cooperative learning application and language proficiency.

5. To discover the mediating effect of cooperative learning application on the relationship between social media usage and language proficiency.

\section{Hypothesis}

The following null hypotheses were treated at the 0.05 level of significance

1. There is no significant relationship between social media usage and language proficiency and social media usage and cooperative learning application and cooperative learning application and language proficiency. 


\section{SJIF Impact Factor 2021: 8.013| ISI I.F.Value:1.241| Journal DOI: 10.36713/epra2016 \\ EPRA International Journal of Research and Development (IJRD)}

2. Cooperative learning application does not significantly mediate the relationship between social media usage and students' language proficiency.

\section{Review of Related Literature}

This part of the study reviews of related literature on the mediating effect of cooperative learning application on the relationship between social media usage and students' language proficiency.

\section{Social Media Usage}

In today's generation, children and even teens spend the majority of their time on social networking websites. In fact, twenty-two percent of teenagers use social networking sites at least ten times a day, and more than half of the teens reported engaging the said sites at least once a day (O'Keefe and Clarke Pearson, 800-804). In addition, Pew Internet and American Life Project stated that more than seventy percent of young adults and youth (ages 12-29) utilize the internet, particularly on social networking sites (Lenhart et al.).

Consequently, Shava and Chinyamurindi mentioned in their study that youth are engaged in social media sites because of three factors, namely: habit, knowledge sharing, and obligation (1-8).

The first indicator of social media is habit. According to Merriam Webster, the term habit refers to something that has become familiar because of frequent or regular repetition. A prior study, for example, attempted to define this as a concept of chronic social media consumption, leading to the coining of terms like media addiction, problematic media use, and media abuse (e.g., Caplan; Morahan-Martin; Young). Satisfaction is an important factor to consider while defining a habit. Thus, satisfaction distinguishes between two highly comparable behavior patterns in the context of social media use: habit and frequent visits or frequent use of a platform.

The second indicator of social media is knowledge sharing. This is the act of providing information or understanding between individuals, teams, communities, or organizations. It is possible to have explicit (procedures and papers) or implicit knowledge (intuitive and experience-based). Sharing information is a deliberate process that not only improves an individual's understanding but also contributes to the growth or enhancement of a body of knowledge that is available to others. Subsequently, Facebook is one method of disseminating information, and this is according to higher education institutions (Ainin et al. 64-73).

The third indicator of social media is an obligation. This is something that binds or obligates a person to perform specific actions whether out of a sense of obligation or as a result of custom, legislation, or other factors. Thus, as John Salmond stated, an obligation is a set of morals or regulations that requires or forces someone to do something. The obligation is effective due to any consequences that may be imposed if the terms are not followed (121).

\section{Language Proficiency}

Due to a variety of political, economic, and technical factors, English has become the worldwide language and the language of global communication. Because of globalization, English has become a crucial component of a successful personality as an essential instrument that is commonly used in worldwide communication. As a result, English continues to be the most frequently spoken language on the planet. The value of English proficiency in boosting export economies, attracting international investment, enhancing service exports, and facilitating global business and cultural links is widely known (Rao 1-8).

As North and Schneider point out, language is a communication device; hence, learners must be aware of these factors to be proficient in the target language such as spoken tasks, comprehension, interaction strategies, qualities of spoken performance, and writing tasks (217-262).

The first indicator of language proficiency is spoken tasks. This is exactly what it sounds like spoken language versus written or non-verbal language. The use of voice or similar utterances to transmit meaning to share thoughts or other information is referred to as spoken language. Thus, research shows that even highly proficient native speakers of English still need to learn 'classroom language' and use it effectively to facilitate language learning in the classroom (Renandya 1-3).

The second indicator of language proficiency is comprehension. Comprehension is understanding the material that necessitates explanations, interpretations, applications, views, empathizing, and self-monitoring among other things. According to the National Institute for Literacy, research has demonstrated that comprehension engagement can help kids learn, retain, and speak about what they read over a thirty-year period (Sargent et al. 361).Thus, the importance of reading comprehension in the literacy curriculum must not be forgotten. Is this foundation still visible in the middle of the deluge of literacy mandates that reading teachers face on a daily basis?

The third indicator of language proficiency is interaction strategies. These are the strategies, techniques, or approaches used to promote teaching and learning through communication, cooperation, support, and feedback. As a result, communication plays a critical role in today's global world, as everyone is involved in communication. The capacity to communicate effectively is widely regarded as the most important of all life skills. It allows us to participate in society, express and transmit information, and learn about the people and the world around us. When the speaker and listener convey the meaning in the first language, good communication is easy to achieve.

The fourth indicator of language proficiency is qualities of speaking performance. It is the ability to express oneself intelligibly, reasonably, and accurately without too much hesitation. Furthermore, before learning to read and write, humans are born with the ability to communicate. Humans spend far more time communicating vocally with 


\section{EPRA International Journal of Research and Development (IJRD)}

language than they do with it in its written form at any given time.

The fifth indicator of language proficiency is written tasks that illustrate the student's ability to come up with a unique good way to look at a topic covered in class. It must demonstrate a critical engagement with a text or topic. Moreover, as Hyland properly points out, teachers' remarks should play an important role in cognitive scaffolding, revealing students' strengths and flaws, and supporting students in the acquisition of disciplinary subject matter and writing discussion (240).

\section{Cooperative Learning Application}

Cooperative learning is a group-based learning strategy. Students in this group seek to teach each other despite having differing understandings. Individual learning approaches (just accept teaching) can provide less understanding than this method (Haq, Najmonnisa, and Saad). Furthermore, prior research have shown that this cooperative strategy can increase substantial results in science and other related domains such as the arts, humanities, and social sciences. Hence, cooperative learning may also be defined as a set of learning practices in which students collaborate to attain common learning objectives (Gillies 39-54).

\section{Theoretical Framework}

This study is anchored on the contention of Krashen's (1985) Input Hypothesis, that people learn a language through being exposed to it or by reading it. A person will learn and produce the language correctly if they have access to a large volume of intelligible input. Given the findings of this study, Filipinos must be inundated with a substantial amount of information via various sources such as social media where English is frequently utilized. The communication process and language acquisition are likely to be experienced by language learners in blogs and microblogging sites, social networks, professional networks, video sharing networks, and contentdriven communities, with 330 different Internet-based programs created as of the end of 2012 (Walaski 40-49).

\section{Independent Variable}

\section{Dependent Variable}

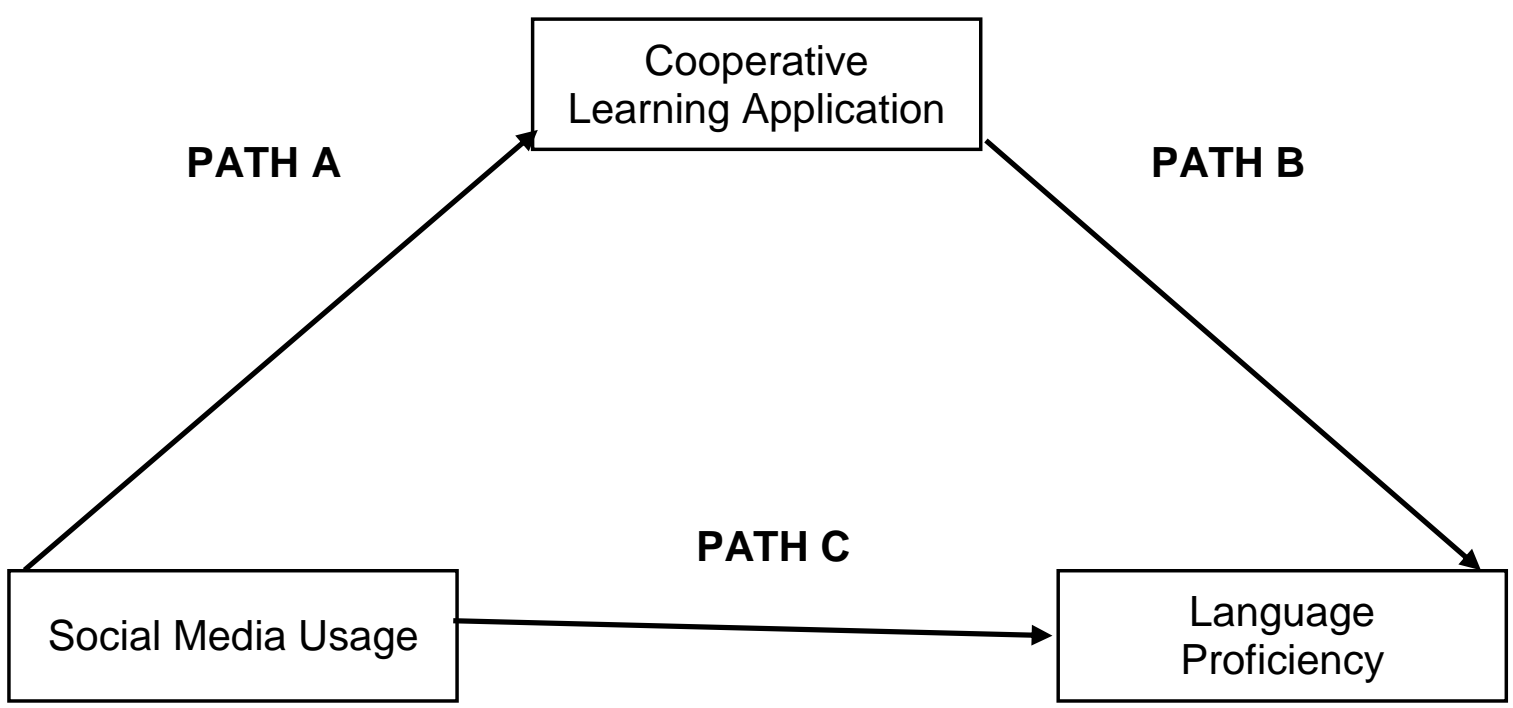

Figure 1. Conceptual Framework Showing the Variable of the Study

\section{Chapter 2 \\ METHOD}

This chapter presented the research methods and data used in the study. The concise chapter entailed an important part of the study.

\section{Research Design}

This research utilized the descriptive-correlation deign. The descriptive study describes students' social media usage during the investigation, while correlational research covers ascertaining statistical associations between two variables (Vanderstoep and Johnston). Additionally, correlation design aims to find out the strength of relationship between the variables being studied (Creswell and Creswell).

\section{Research Locale}

This study was conducted in one of the prestigious universities and biggest private, non-sectarian university in Davao. Through the years, this university became one of the fastest-growing schools in Davao region, now it has branches and campuses in Region 11.

\section{Research Respondents}

The study employed stratified random sampling in selecting the respondents of this study. For the school year 


\section{EPRA International Journal of Research and Development (IJRD)}

Volume: 7 | Issue: 2 | February 2022

- Peer Reviewed Journal

2019-2020, 328 HUMSS students in grades 11 and 12 from one of Davao City's largest universities responded.

\section{Research Instrument}

A three-part questionnaire was used in the study, one for each variable. Expert recommendations were used to validate and revise the document. The researcher conducted a preliminary survey with a total of 30 respondents for reliability testing before conducting the actual survey. The Cronbach's alpha was used to conduct an internal consistency type of validity test on the preliminary data gathered.

\section{Data Collection}

In acquiring the data, the researcher explored the following procedures. After the research project was proposed, the researcher modified a downloaded questionnaire based on the obtained articles, journals, and books that served as the primary basis for investigations.

\section{Chapter 3 \\ RESULTS}

The presentation, analysis, and interpretation of the acquired data are depicted in this part of the paper based on the research objectives of this study.

\section{Social Media Usage}

In Table 1, the weighted means of each criterion were computed, in which the level of social media usage has a weighted mean of 3.56 with a standard deviation of 0.61 and a descriptive interpretation of high.

Table 1

Level of Social Media Usage

\begin{tabular}{llll}
\hline Indicator & SD & Mean & Descriptive Level \\
\hline Habit & 0.81 & 3.56 & High \\
Obligation & 0.76 & 3.44 & High \\
Knowledge Sharing & 0.67 & 3.67 & High \\
\hline Overall & $\mathbf{0 . 6 1}$ & $\mathbf{3 . 5 6}$ & High \\
\hline
\end{tabular}

\section{Language Proficiency}

As revealed in Table 2, the level of language proficiency with an overall weighted mean score of 3.65 and a standard deviation of 0.59 has a verbal interpretation of high.

Table 2

Level of Language Proficiency

\begin{tabular}{llll}
\hline Indicator & SD & Mean & Descriptive level \\
\hline Spoken Tasks & 0.66 & 3.57 & High \\
Comprehension & 0.69 & 3.66 & High \\
Interaction Strategies & 0.66 & 3.56 & High \\
Writing Skills & 0.77 & 3.99 & High \\
Qualities of Spoken & 0.63 & 3.46 & High \\
Performance & & & \\
\hline Overall & $\mathbf{0 . 5 9}$ & $\mathbf{3 . 6 5}$ & High \\
\hline
\end{tabular}

\section{Cooperative Learning Application}

In Table 3, the level of cooperative learning application has a weighted mean of 4.19 with a standard deviation of 0.52 and a verbal interpretation of high.

Table 3

Level of Cooperative Learning Application

\begin{tabular}{llll}
\hline Indicator & SD & Mean & Descriptive level \\
\hline Positive Interdependence & 0.73 & 4.51 & Very High \\
Assessment & 1.05 & 3.83 & High \\
Tutoring & 0.79 & 4.15 & High \\
\hline Overall & $\mathbf{0 . 5 2}$ & $\mathbf{4 . 1 9}$ & High \\
\hline
\end{tabular}

Relationship between Social Media Usage and Language Proficiency

Depicted in Table 4.1 is the result of the test of the relationship between social media usage and language proficiency. This relationship was tested at a 0.05 level of significance. 
Table 4.1

Correlation between Social Media Usage and Language Proficiency

Language Proficiency

Social Media Usage

$\begin{array}{lllllll} & \begin{array}{l}\text { Spoken } \\ \text { Tasks }\end{array} & \begin{array}{l}\text { Compre } \\ \text { hension }\end{array} & \begin{array}{l}\text { Interaction } \\ \text { Strategies }\end{array} & \begin{array}{l}\text { Qualities of } \\ \text { Spoken } \\ \text { Performance }\end{array} & \begin{array}{l}\text { Writing } \\ \text { Skills }\end{array} & \text { Overall } \\ \text { Habit } & .206^{*} & .181^{*} & .212^{*} & .267^{*} & .103^{*} & .221^{*} \\ & (.000) & (.000) & (.000) & (.000) & (.000) & (.000) \\ \text { Obligation } & .255^{*} & .270^{*} & .298^{*} & .278^{*} & 191^{*} & 297^{*} \\ \text { Knowledge } & (.000) & (.000) & (.000) & (.000) & (.000) & (.000) \\ \text { Sharing } & .370^{*} & .322^{*} & .369^{*} & .369^{*} & .278^{*} & .394^{*} \\ \text { Overall } & (.000) & (.000) & (.000) & (.000) & (.000) & (.000) \\ & \mathbf{. 3 3 3} * & \mathbf{. 3 1 1} * & \mathbf{. 3 5 3} * & \mathbf{. 3 6 9 *} & \mathbf{. 2 2 6} * & \mathbf{. 3 6 6} * \\ & \mathbf{( . 0 0 0 )} & \mathbf{( . 0 0 0 )} & \mathbf{( . 0 0 0 )} & \mathbf{( . 0 0 0} & \mathbf{( . 0 0 0 )} & \mathbf{( . 0 0 0 )}\end{array}$

The overall result reflects that social media usage is positively correlated with language proficiency since the overall $\mathrm{r}$-value is .366 with a p-value <.05, hence rejecting the null hypothesis.
Relationship between Social Media Usage and Cooperative Learning Application

Displayed in Table 4.2 is the result of the test of the relationship between social media usage and cooperative learning application. The result shows that the overall values reveal a positive and significant relationship between social media usage and cooperative learning application $(\mathrm{r}=.372$, $\mathrm{p}<.05)$.

Table 4.2

Correlation between Social Media Usage and Cooperative Learning Application

\begin{tabular}{llllll} 
& \multicolumn{2}{c}{$\begin{array}{c}\text { Social Media } \\
\text { Habit }\end{array}$} & $\begin{array}{l}\text { Usage } \\
\text { Obligation }\end{array}$ & Knowledge sharing & \multicolumn{1}{c}{ Overall } \\
Cooperative & Learning & $.199 *$ & $.302^{*}$ & $.434^{*}$ & $.372^{*}$ \\
Application & & $(.000)$ & $(.000)$ & $(.000)$ & $(.000)$
\end{tabular}

Relationship between Cooperative Learning Application and Language Proficiency

Illustrated in Table 4.3 is the result of the test of the relationship between cooperative learning application and language proficiency. The result shows that the overall values reveal a positive and significant relationship between language proficiency and cooperative learning application.

Table 4.3

Correlation between Cooperative Learning Application and Language Proficiency

$\begin{array}{lc}\text { Language Proficiency } & .363^{*} \\ \text { Spoken Tasks } & (.000) \\ & .357^{*} \\ \text { Comprehension } & (.000)) \\ & .330^{*} \\ \text { Interaction Strategies } & (.000) \\ \text { Qualities of Spoken Performance } & .371^{*} \\ \text { Writing Skills } & (.000) \\ & .336^{*} \\ \text { Total } & (.000) \\ & \mathbf{4 0 8 *} \\ & \mathbf{( . 0 0 0 )}\end{array}$




\section{EPRA International Journal of Research and Development (IJRD)}

Volume: 7 | Issue: 2 | February 2022

- Peer Reviewed Journal

The overall result reflects that cooperative learning application is positively correlated with language proficiency since the overall $\mathrm{r}$-value is .408 with a $\mathrm{p}$-value $<.05$, hence rejecting the null hypothesis. Hence, there is a positive association between the two variables.

\section{Mediation Analysis of the Three Variables \\ PARTIAL MEDIATION (WITH SIGN UNCHANGED)}

\begin{tabular}{|lll|rrrrr|}
\hline & & & Estimate & S.E. & C.R. & P & Label \\
\hline CLA & $<---$ & SMU & .316 & .044 & 7.251 & $* * *$ & \\
LP & $<---$ & SMU & .237 & .050 & 4.715 & $* * *$ & \\
LP & $<---$ & CLA & .354 & .059 & 5.987 & $* * *$ & \\
\hline
\end{tabular}

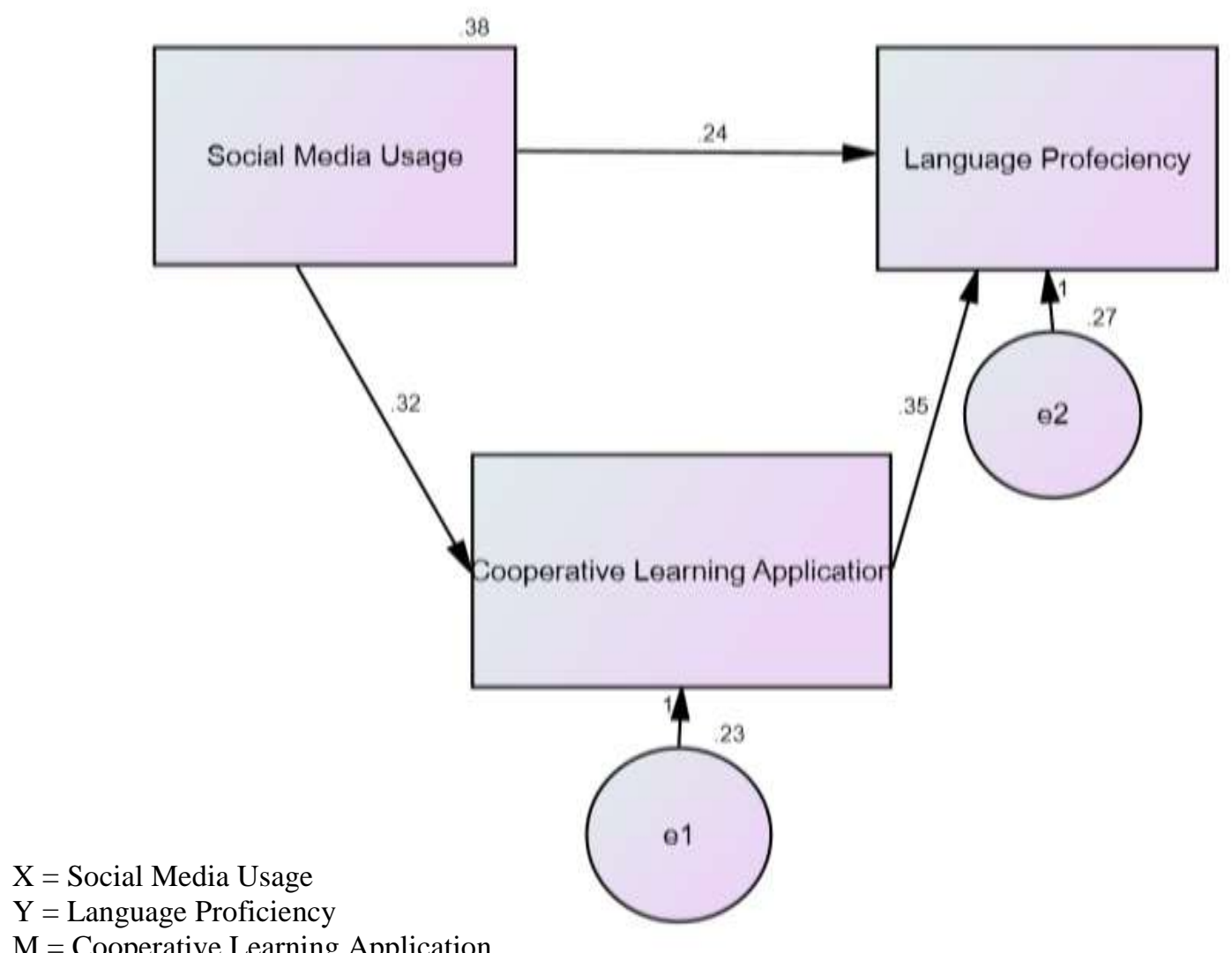

$\mathrm{M}=$ Cooperative Learning Application

Figure 3. Results of Mediation Computation

\section{RESULTS}

The results of Path Analysis demonstrate that the paths SMU (X) to CLA (M); CLA (M) to LP (Y); and SMU (X) to LP (Y) were all significant with the sign unchanged, implying that CLA mediates the interaction between SMU and LP to some extent. Figure 3 illustrates that for every unit increase in Social Media Usage, a 0.32 unit rise in M is seen (CLA). Also, for every unit increase in Cooperative Learning Application, there is a 0.35 corresponding increase in Language Proficiency.

\section{Chapter 4 \\ DISCUSSION}

Contained in this chapter is the discussion on the data gathered on cooperative learning application, social media usage, and language proficiency.

\section{Social Media Usage}

The high level of social media usage of students is due to the high rating given by the respondents on habit, knowledge sharing, and obligation. The students are manifesting high social media usage because it is widely used nowadays, most especially Facebook. Likewise, students believe that helping the Facebook community to accumulate or enrich knowledge is part of being a members of the group.

\section{Language Proficiency}

There is a high level of language proficiency since the students obtained a high rating on spoken tasks, comprehension, interaction strategies, writing skills, and qualities of spoken performance. Students are demonstrating 


\section{SJIF Impact Factor 2021: 8.013| ISI I.F.Value:1.241| Journal DOI: 10.36713/epra2016 \\ EPRA International Journal of Research and Development (IJRD)}

Volume: 7 | Issue: 2 | February 2022

- Peer Reviewed Journal

language proficiency in order to meet the increased demand for English language study.

\section{Cooperative Learning Application}

The high level of cooperative learning application revealed that students view cooperative learning application positively as a helpful strategy in learning since they showed a high rating on positive interdependence, interaction, social skills, group reflection, heterogeneity, assessment, and tutoring. These factors help them develop their language since it is parallel with the study of Kagan, that positive learning environment leads to higher academic accomplishment for all members of the group, as well as the development of crucial social skills, improved communicative ability, and a positive model for lifetime learning

\section{Significant Relationship between Social Media Usage and Language Proficiency}

The test of the relationship between social media usage and language proficiency revealed a significant relationship between social media usage and language proficiency. This implies that the students' social media usage is correlated to language proficiency. In other words, the increase of social media usage would also likely increase their language proficiency. Furthermore, the result of this study confirms the contention of Krashen, that people pick up a language through being exposed to it or by reading materials about it.

\section{Significant Relationship between Social Media Usage and Cooperative Learning Application}

The test of the relationship between students' social media usage and cooperative learning application shows that there is a positive and significant relationship between students' social media usage and cooperative learning applications. This means that the increase in students' social media usage would also likely increase cooperative learning application. This is similar to the result of the study of Shoshani and Braun which claims that social media usage encourages cooperative learning and eventually, creative learning.

\section{Significant Relationship between Cooperative Learning Application and Language Proficiency}

The test of the relationship between cooperative learning application and language proficiency revealed a positive and significant relationship between the indicators of language proficiency. This means that the increase in students' cooperative learning application would also likely increase language proficiency. This is congruent with what the study of Johnson et al. claimed, that to be a scholars worldwide and at home there has to be an efficient teaching strategy in foreign and second language instruction.

\section{The Mediating Effect of Cooperative Learning Application}

The mediation analysis reveals that cooperative learning applications partially mediate the relationship between social media usage and language proficiency. The partial mediation may not totally claim that students' cooperative learning application is the very reason why and how students' social media usage can influence their language proficiency. This indicates that students' cooperative learning applications can partly explain how social media usage can influence their language proficiency.

\section{CONCLUSION}

As can be gleaned in the findings of this study, conclusions are drawn in this section. The findings of this study confirm the assumptions about the mediating effect of the students' cooperative learning application on the relationship between social media usage and language proficiency. This was confirmed by the theory of Krashen that students learn the language by being exposed to it or by reading it, which students nowadays are using different social media platforms. When a student has a lot of intelligible input that could be coming from different social media, he or she is more likely to learn and produce the language appropriately. Given the findings of this study, Filipinos must be inundated with a substantial amount of information through various channels, such as social media, where English is frequently used.

\section{Recommendations}

A number of recommendations are offered based on the foregoing finding and conclusions. Since there is a high level of use of social media, a high level of application for cooperative learning, and a high level of language proficiency, it is suggested that students maintain or even improve for better language learning outcomes. Furthermore, to improve the level of application for cooperative learning, the use of social media and language proficiency, the school may undertake further training courses and seminars in collaboration with the Department of Education to help improve teachers and students' use of the application for cooperative learning and social media as tools for language proficiency. 